\title{
High-performance Liquid Chromatography/Tandem Mass Spectrometry
}

National Cancer Institute

\section{Source}

National Cancer Institute. High-performance Liquid Chromatography/Tandem Mass

Spectrometry. NCI Thesaurus. Code C120691.

An analytical technique wherein high performance liquid chromatog raphy is coupled to tandem mass spectrometry in order to separate, identify, and quantify substances in a sample. 